\title{
Festas Populares na Bahia: gestão e dinâmica identitária ${ }^{1}$
}

\author{
Fiestas Populares en Bahia: gestión y dinámica de la identidad
}

Popular Festivities in Bahia: management and identity dynamics

\author{
Eduardo Davel ${ }^{2}$ \\ Marcelo Dantas ${ }^{3}$
}

Palavras-chave:

Festas populares

Identidade

Gestão

Bahia

\section{Resumo:}

Festas populares são experiências coletivas que expressam a identidade de uma comunidade, de uma sociedade, de um povo. Elas se perpetuam em forma de tradição e se renovam na dinâmica cultural em permanente contemporaneidade. Os conhecimentos existentes sobre as festas populares são multidimensionais: dimensão religiosa, cultural, simbólica, econômica, política, entre outras. Todavia, sabemos pouco sobre sua dimensão organizativa. O objetivo desse artigo é mergulhar no universo das festas populares, em particular nas festas de Salvador, para discutir uma concepção de gestão pautada pela prática da negociação de sentidos - entre os diferentes organizadores da festa - que move a dinâmica identitária. Pensar as festas populares a partir dessa chave interpretativa significa um movimento duplo: de um lado, conhecer a lógica organizativa que explica o florescimento das festas populares e, de outro lado, ampliar nosso entendimento sobre a gestão desse tipo de fenômeno organizacional.

\footnotetext{
1 Texto recebido em 26/03/2019 e aceito para publicação em 23/10/2019.

2 Eduardo Paes Barreto Davel. Doutor em Administração pela École des Hautes Études Commerciales de Montreal, Canadá. Pesquisador visitante na Graduate Faculty of Political and Social Science da New School for Social Research (New York, EUA). Professor da Universidade Federal da Bahia, Brasil. Contato: davel.eduardo@gmai.com - https://orcid. org/0000-0003-0610-6474
}

3 Marcelo Dantas. Doutor em Sociologia pela Universidade de Paris VII - Dennis Diderot. Professor Adjunto e Coordenador do Curso Superior Tecnológico em Política e Gestão Cultural da Universidade Federal do Recôncavo da Bahia, Brasil. Contato: mdantas50@gmail.com 


\section{Resumen:}

Las fiestas populares son experiencias colectivas que expresan la identidad de una comunidad, de una sociedad, de un pueblo. Ellas se perpetúan en forma de tradición y se renuevan en la dinámica cultural en permanente contemporaneidad. Los conocimientos existentes sobre las fiestas populares son multidimensionales: dimensión religiosa, cultural, simbólica, económica, política, entre otras. Sin embargo, sabemos poco sobre su dimensión organizativa. El objetivo de este artículo es sumergirse en el universo de las fiestas populares, en particular en las fiestas de Salvador, para discutir una concepción de gestión pautada por la práctica de la negociación de sentidos - entre los diferentes organizadores de la fiesta - que mueve la dinámica identidaria. Pensar las fiestas populares a partir de esta clave interpretativa significa un doble movimiento: por un lado, conocer la lógica organizativa que explica el florecimiento de las fiestas populares y, por otro lado, ampliar nuestro entendimiento sobre la gestión de ese tipo de fenómeno organizacional.

\section{Palabras clave:}

Fiestas populares

Identidad

Gestión

Bahia

\section{Keywords:}

Popular festivities

Identity

Management

Bahia

\section{Abstract:}

Popular festivals are collective experiences that express the identity of a community, a society, a people. They are perpetuated in the form of tradition and are renewed in the cultural dynamics in permanent contemporaneity. Knowledge about popular festivals is multidimensional: religious, cultural, symbolic, economic, political, among others. However, we know little about its organizational dimension. The purpose of this article is to delve into the universe of popular festivals, particularly at the celebrations in Salvador, to discuss a management conception guided by the practice of the negotiation of meanings - among the different party organizers - that moves the identity dynamics. Thinking about popular festivals based on this interpretative key means a double movement: on the one hand, to know the organizational logic that explains the flourishing of popular festivals and, on the other hand, to broaden our understanding of the management of this type of organizational phenomenon. 


\section{Festas Populares na Bahia: Gestão e Dinâmica Identitária}

\section{Introdução}

As festas intrínsecas à história da humanidade se apresentam em múltiplos formatos, funções e espaços. As festas populares compõem um tipo específico de festa, em que a efervescência organizadora emerge da população. O conhecimento acumulado sobre as festas populares envolvem várias dimensões: sociais, religiosas, culturais, simbólicas, políticas, dentre outras (ARAÚJO, 2004; CARNEIRO, 1974; CAVALCANTI, 2013; CAVALCANTI; GONÇALVES, 2009; FERRETI, 2012; ISAMBERT, 1982; JANCSÓ; KANTOR, 2001a, 2001b; MORAES FILHO, 1979; PASSOS, 2002; PEREZ, 2002; RIBEIRO, 2002; RUBIM; MIRANDA, 2012; SILVA; MIGUEZ, 2014; TINHORÃO, 2002, 2008; ZALUAR, 1983). Todavia, não dispomos de informações sobre as forças organizadoras que dão vida a essas festas. A gestão das festas populares não se equipara com a imagem tradicional de gestão como forma linear, instrumental e previsível de controle. Pela complexidade do fenômeno 'festas populares', a concepção tradicional de gestão deve ser desafiada e repensada. O objetivo desse artigo é mergulhar no universo das festas populares, em particular nas festas de Salvador, para discutir uma concepção de gestão pautada pela prática da negociação de sentidos - entre os diferentes organizadores da festa - que move a dinâmica identitária. Pensar as festas populares a partir dessa chave interpretativa significa um movimento duplo: de um lado, conhecer a lógica organizativa que explica o florescimento das festas populares e, de outro lado, ampliar nosso entendimento sobre a gestão desse tipo de fenômeno organizacional.

Festas populares são celebrações enraizadas na cultura popular e na identida- de cultural de uma sociedade que se constrói ao longo do tempo (RIBEIRO, 2002; FARIAS; MIRA, 2014; STOREY, 1993, 2003, 2015; STRANATI, 1995; GROSSBERG, 1997). São manifestações culturais que representam patrimônio imaterial da humanidade (DUVIGNAUD, 1973). Fortalecem laços comunitários e atraem interesses de agentes diversos, pelo seu poder de ativar o desenvolvimento local e o turismo (CASTRO, 2006; RIBEIRO, 2004). No mundo contemporâneo, marcado de forma ampla pelas ofertas de turismo das mais diversas regiões do planeta, as festas populares de um povo, de uma cidade, de uma comunidade são, cada vez mais, um diferencial buscado para a dinâmica da economia do lugar. Por isso, é uma tendência mundial que as manifestações culturais interessem às várias esferas de governo e ao capital.

A gestão dessas manifestações culturais tende a ser, no mundo contemporâneo, uma expressão das novas formas de gestão coletiva ou em rede, estabelecendo uma articulação entre o público, o privado e o comunitário. Isso exige uma governança cuidadosa, uma articulação bem azeitada, com cada fio dessa rede sendo tecido num cuidadoso bordado, para que cada parte mantenha sua representatividade, seu papel e sua atuação coerentes com sua representação no coletivo e que essa gestão não signifique - sob pena de fracasso - uma ameaça à historicidade e evolução dessas manifestações, que, em caso de intervenções indesejadas podem correr o risco de se desfigurar ao ponto de perder a sua força e, em consequência, a sua atratividade para o turismo, matando o seu potencial econômico para o local e a comunidade.

Nas cidades, as festas populares se perpetuaram graças às iniciativas das comunidades responsáveis pela manutenção dessas tradições, passadas de pai pra filho e são reiteradas coletivamente através de celebrações, representações e festas. Entretanto, cada vez mais, no mundo 
contemporâneo, essas festas passaram a significar um importante momento para a economia das cidades, levando a que as esferas de governo e os agentes econômicos se interessassem pela sua existência, perpetuação e difusão fora dos limites municipais. Elas estão no centro de qualquer política de turismo seja no âmbito da cidade, da região ou do país, a depender da sua grandeza e impacto no imaginário fora dos limites da comunidade que a produz.

Consequentemente, as festas populares não devem ser confundidas com os conceitos de eventos ou projetos culturais, pois suas lógicas são atravessadas por interesses múltiplos, situados ao longo de uma história e de uma identidade cultural local. Eventos e projetos podem ser manifestação e gestão de iniciativas e criação individual, ao passo que as festas populares não o podem. Para entender melhor a singularidade das práticas de gestão subjacentes às festas populares, necessitamos mergulhar no universo da identidade, entendida como dinâmica que se constrói a partir da negociação permanente dos sentidos atribuídos à festa. Para explorar essa dinâmica identitária e suas repercussões em termos de gestão, nos concentraremos nas festas populares de Salvador, Bahia.

Realizada no campo das festas populares de Salvador, a pesquisa empírica foi orquestrada por uma metodologia conduzida pelos dois pesquisadores durante 20 anos de participação nas festas e em processos organizativos que sustentam a gestão das festas. O estranhamento ocorreu durante a interação entre os pesquisadores, considerando que um deles é estrangeiro ao contexto cultural da Bahia e outro familiar a este contexto. Essa composição de familiaridade e não-familiaridade gerou um estado permanente de reflexividade durante a interpretação do material empírico. A observação participante relativa às festas e no processo de organização das festas é reforçada por produções acadêmicas (livros, dissertações, teses, artigos) e jornalísticas sobre festas populares na Bahia.

\section{Festas populares, dinâmica identitária e gestão}

As festas populares são atividades imprescindíveis, tanto em diversos lugares quando diversos tempos (passado e contemporaneidade). Elas permitem a distinção cultural de comunidades, reatualizam as tradições, os valores, representam momentos de congregação coletiva e reforçam a socialização em torno de crenças compartilhadas. Surpreendentemente, são mais frequentes, atuais e relevantes do que imaginamos na vida cultural das sociedades contemporâneas. São consideradas patrimônios culturais imateriais dentro da lógica da diversidade cultural promovida pela UNESCO. Nas últimas décadas, a UNESCO tem atuado como um fórum internacional amplificador do debate sobre a questão da diversidade cultural, içando-a a um lugar de destaque na agenda política internacional. A promulgação de instrumentos internacionais (Declaração e a Convenção da Diversidade Cultural) expressa não somente o protagonismo que a questão da diversidade tem ganhado, como também o papel da UNESCO na disseminação e valorização da ideia de diversidade cultural como um bem universal (PITOMBO, 2011).

As festas populares podem ativar a lógica de mercado, mobilizando recursos, gerando emprego e renda, dinamizando economias nacionais e locais, ativando o turismo, gerando impactos significativos no comércio, no artesanato, na rede de hospedagem e alimentação. São muitas organizações que se envolvem na produção da festa, o que articula setores públicos e privados. Nesse sentido, as festas podem ser reconhecidas como oportunidades de investimento e arena de empreendedorismo, se destacando como força motriz das economias culturais e criativas (MOERAN; PEDERSEN, 2011). 
No contexto das indústrias culturais, feiras e festivais foram estudados na ótica de produção, negociação e transmissão de valores, com enfoque nas atividades de investimento e empreendedorismo (MOERAN et al., 2011). Todavia, não se trata de festas populares, da identidade cultural nem da lógica de gestão intrínseca do processo de organização destas festas. Outros estudos aprofundaram a compreensão das festas populares como negócio (FISCHER, 1996; MIGUEZ, 1996; LOIOLA; MIGUEZ, 1996; FARIAS, 2011), como expressão de lideranças singulares (DANTAS, 1996, 2000) e como espaço de colaboração interorganizacional (CABRAL et al., 2013). Os processos de colaboração entre entidade públicas e privadas no planejamento e operação do Carnaval de Salvador foi analisado, destacando-se suas tensões, conflitos e articulações (CABRAL et al., 2013). Organizações do carnaval - e não a festa do carnaval em si - foram consideradas em seus aspectos de gestão, como o Olodum (DANTAS, 1994).

Em suma, nenhum estudo enfocou as festas populares em suas entranhas organizativas, sob a ótica das singularidades de sua gestão, por múltiplos atores sociais, tendo a identidade cultural como força motriz. A identidade é uma categoria que chama a atenção dos pesquisadores há muito tempo, refletindo em pesquisas que se desdobram em vários campos e escalas de análise. Encontramos reflexões sobre identidade organizacional (ALVESSON et al., 2008; KNIGHTS; WILLMOTT, 1999; GIOIA et al., 2013; HATCH; SCHULTZ, 2004; SCHULTZ et al., 2012; CARRIERI et al., 2008), identidade no consumo (RUVIO; BELK, 2013), no trabalho (BEECH et al., 2008; BREINER et al., 2006; SAINSAULIEU, 1977, IBARRA; PETRIGLIERI, 2010), na profissão (DUBAR, 1998; SLAY; SMITH, 2011, IBARRA, 1999) e na carreira (IBARRA, 2003, IBARRA; DESHPANDE, 2007). A identidade cultural pode perpassar essas várias escalas, mas encontra seu terreno mais consolidado no âmbito da sociedade, quando pensada em relação a comunidades, territórios, o Estado-nação e a globalização (DU GAY et al., 2000; HALL, 2006; HALL; DU GAY, 1996; HOLLAND et al., 1998; SILVA et al., 2014; BAUMAN, 2005; ECHEVERRI PERICO, 2009; HAESBAERT, 1997; WOODWARD, 2006; SAQUET; BRISKIEVICZ, 2009).

Consideramos a identidade como uma dinâmica. A identidade é entendida como um 'sentimento de pertencimento', como fonte de significado e experiência de um povo (CASTELLS, 1999), regida por um processo dinâmico de identificação/diferenciação (SILVA, 2014; WOODWARD, 2014; HALL; DU GAY, 1996), construções simbólicas oriundas de perenes lutas de representação (CHARTIER, 2002). A identidade é um processo corporificado (WOODWARD, 2006) e vivido como experiência emocional (CRAIB, 1998). A identidade envolve prática, embates, negociações de sentido dentro de contextos de atividade e subjetividades (HOLLAND et al., 1998).

As festas populares exigem esse olhar mais dinâmico e integrado da identidade cultural. Trata-se de um olhar que busque integrar as diversas escalas que a identidade concilia durante a organização, planejamento e realização de uma festa popular na prática. Identidades territoriais, comunitárias, nacionais, regionais, globalizadas, profissionais, organizacionais, dentre outras, atuam ao mesmo tempo no contexto de festas populares. Essa integração multi-escalar da identidade torna-se mais explícita, dinâmica, intensa e estrategicamente determinante para todos os envolvidos em sua organização e gestão. A dinâmica identitária emerge e se renova a partir de conflitos envolvendo atores diversos que atribuem valor e sentido distintos à festa.

Quando se organiza uma festa popular, a identidade cultural da manifestação está enraizada em uma tradição territorializada. Envolve um passado ativado nas tradições do território, mas também nas 
formas e processos de negociação de sentido que criam consensos e viabilizam materialmente a manifestação ao longo dos tempos. Essas formas e processos dependem das identidades profissionais, organizacionais e artísticas das pessoas comprometidas com a realização da festa. Além disso, por seu envolvimento sacralizado e corporal, festas também envolvem seus participantes em uma identidade que é experimentada, vivenciada, nos sentimentos, nas emoções e na corporeidade (CRAIB, 1998; WOODWARD, 2006). Participar de uma manifestação não é pensar ou racionalizar a experiência cultural, mas, sobretudo, experimentar, sensorialmente, simbolicamente e corporalmente, a manifestação em toda a sua força e forma cultural.

\section{As festas populares na Bahia: dinâmica identitária na organização}

$\mathrm{Na}$ Bahia, as festas populares são intensas, abundantes, plurais, sincreticamente diversas, historicamente antigas. Por isso, torna-se um contexto propício para nos debruçarmos sobre seus aspectos identitários e organizacionais. Toda cidade tem seus momentos de celebração coletiva, ou pelo menos um dia no ano dedicado à fundação daquela cidade ou ao santo padroeiro, ou a um evento que se tornou marca fundamental daquele lugar. Salvador, capital da Bahia - que foi durante os três primeiros séculos do Brasil a sua capital - se diferencia pela opulência festiva. A cidade não tem apenas uma data ou evento de celebração da sua identidade, mas um calendário de cerca de três dezenas de festas, espalhadas por todo o ano, cujo destaque é, sem dúvida, o chamado de Ciclo de Festas de Largo que começa em dezembro e segue até o carnaval, durante praticamente três meses. São festas populares como a Festa de Santa Bárbara, Festa de Nossa Senhora da Conceição da Praia, Festa de Santa Luzia, Festa da Boa Viagem, Festa da Lavagem do Bomfim, Festa da Segunda-feira
Gorda da Ribeira, Festa de São Lázaro, Festa de lemanjá, Festa de Itapuã, Carnaval. Na contemporaneidade, algumas dessas festas perderam importância e tiveram a participação popular reduzida, enquanto outras continuam a mobilizar enormemente a população da cidade.

Dentro de uma retrospectiva histórica, a primeira festa popular brasileira com ritualística de festa ocorreu na Bahia em 13 de junho de 1549, transcorridos apenas 74 dias do desembarque de Tomé de Souza e com a Cidade do Salvador ainda estado de canteiro de obras (VARÓN CADENA, 2015). Estamos falando dos primeiros momentos de ocupação do Brasil pelos portugueses que o descobriram ainda em 1500. A cidade de Salvador foi criada, planejada, projetada pelo mestre-arquiteto Luis Dias e construída para ser a capital do Brasil e sede do governo colonial português. Essa festa, relatada em carta do Padre Manoel da Nóbrega, foi a Procissão de Corpus Christi, como de resto é de origem religiosa católica todo o ciclo de festas populares que a Bahia iria desenvolver depois daquela espécie de batismo. Essa multiplicação de procissões e festas religiosas foram agregando, no seu contexto, camadas da população que de uma ou de outra forma interferiram na sua ritualística original, introduzindo elas próprias elementos que um dia convencionou-se chamar de profanos para estabelecer uma clara diferenciação entre os propósitos da Igreja e da participação popular (SERRA, 2009).

Centro da economia e do poder colonial e mesmo quando perdeu essa centralidade para o sul do país entre o final do século XVIII - exatamente desde 1763, quando a capital da colônia se transferiu para o Rio de Janeiro - e durante o século XIX, quando o modelo econômico agrário entra em processo irreversível de decadência, num mundo em processo acelerado de industrialização, a Bahia já misturava suas sérias responsabilidades, trabalho, econo- 
mia e riqueza, com as mais grandiosas festas, desde então já multiculturais e como até hoje, misturando o sagrado e o profano sem nenhuma culpa.

Tantas eram as festas populares realizadas na Bahia nos séculos XVIII e XIX que o erário aportava um volume de recursos desproporcional para essas festas que tinham o dobro do orçamento destinado às obras públicas. As festas populares movimentavam muito dinheiro. Parte desses recursos retornava ao erário através de impostos, em especial, do comércio informal e também através das taxas de importação que eram elevadas e, praticamente, tudo que se vendia na Bahia era oriundo da Europa. Todos os setores econômicos lucravam, inclusive o transporte público, então emergente (VARÓN CADENA, 2015).

Dentro de um percurso cronológico, a primeira festa de largo é a Festa de Santa Bárbara (lansã no Candomblé), em 04 de dezembro. Durante alguns anos, essa festa passou a ser realizada apenas para um número pequeno de devotos, até que recentemente voltou com muita força, sendo hoje não só a abertura do ciclo, mas uma de suas festas mais importantes. Ela é seguida pela Festa da Conceição da Praia, que acontece em 8 de dezembro. A partir de então, a cada semana, a festa e a multidão se deslocam para outra praça e outra igreja numa sucessão que dura praticamente três meses. Isso mobiliza a população da cidade, num ritmo de autocelebração da sua identidade. Além da Festa da Conceição (que é Oxum no candomblé), as mais importantes são a Festa do Bonfim, ou Oxalá (segunda quinta-feira de janeiro) e a Festa do Rio Vermelho ou Festa de lemanjá, no dia 2 de fevereiro. Esse ciclo de festas, não por acaso, se encerra em seu ápice, numa espécie de celebração definitiva e totalizadora: o Carnaval.

Essa profusão de festas vai resultar num calendário voltado para a celebração do sincretismo religioso baiano, juntando candomblé e catolicismo, assim como também expressões do sagrado e do profano, indissociáveis, em forma de festas de largo. As festas de largo, uma manifestação típica de Salvador, se estendem por todo o verão, de dezembro até fevereiro ou março. Elas têm um sentido de abrangência que é dado pelo seu caráter migratório, percorrendo largos e igrejas de toda a cidade.

\subsection{0 sincretismo como expressão cultural das festas populares}

As Festas de Largo se distinguem de outras celebrações por muitas razões. A principal delas é o fato de serem uma expressão do sincretismo religioso singular que caracteriza a cidade de Salvador. $O$ sincretismo é um desses conceitos de múltiplas definições, mas implicam sempre em uma relação entre duas culturas, que se influenciam mutuamente. Ao falarmos de sincretismo religioso, e como ele se verifica historicamente no Brasil e na Bahia, um dos primeiros e mais consistentes olhares foi o de Roger Bastide (1971), que alerta para o fato fundamental: o sincretismo é fluido e móvel, não é rígido nem cristalizado. Elas sempre acontecem em celebração de um santo católico e seu orixá correspondente no candomblé. Por essa razão, elas mobilizam os católicos, os praticantes de candomblé e uma grande parte da população que cultua, sem nenhum drama identitário, moral ou cultural, as duas religiões.

Com a presença cada vez mais forte, em população e influência cultural dos negros, pródigos em danças e expressões musicais, os eventos religiosos foram cada vez mais invadidos pelo profano. Chegou-se ao ponto de o arcebispado na Bahia estabelecer, em 1707, em um sínodo diocesano, a proibição, dentre outras manifestações, de danças e folias nas igrejas (VARÓN CADENA, 2015). Como a maioria das leis do Brasil colonial, essa nunca "pegou". Os baianos continuaram, a partir 
dessas práticas de reunir o sagrado e o profano em uma mesma celebração, festa, manifestação, um processo histórico de elaborado sincretismo religioso, onde os santos católicos passaram a "abrigar" nas suas imagens e nomes, os orixás do Candomblé, a religião de origem africana que iria secularmente ser compartilhada com o catolicismo até a contemporaneidade.

$\mathrm{Na}$ Bahia, a ancestralidade negra se mantém viva através de formas de organização cultural que garantem a continuidade da tradição trazida pelos negros africanos desde os primeiros tempos da escravidão. Essas formas de organização cultural foram mantidas através de uma forte ligação com as raízes negras de origem africana. Elas se manifestam no canto, na música, na vestimenta, nas cores, nos símbolos sagrados e nas práticas religiosas (SIQUEIRA, 1989).As raízes africanas estão também presentes nas manifestações populares, onde se misturam negros, mestiços e brancos através de um tipo de relação e de integração, possível na Bahia, apesar das desigualdades sociais.

As festas dedicadas aos santos da Igreja Católica são um exemplo da amplitude dessas relações. No mesmo espaço, a população louva seus santos católicos, reverencia seus orixás e pratica os rituais sagrados e profanos, usando danças e ritmos herdados dos ancestrais africanos tão distantes no tempo, mas tão vivos na percussão dos tambores e das batidas dos corações. A contemporaneidade traz as marcas dessa história e das singularidades das relações entre os brancos de origem europeia, os negros africanos e os mestiços brasileiros, em permanente estado de conflito e negociação (DANTAS, 2000).

As Festas de Largo também são a expressão da principal característica cultural da cidade de Salvador: a sociabilidade da rua. Desde sua fundação em 1549, como capital do Brasil, Salvador da Bahia é uma cidade onde uma parte essencial das relações sociais, culturais, comerciais e religiosas acontece na rua. Foi assim desde as origens de cidade portuária que atraía estrangeiros do mundo inteiro e cujo porto era o mais importante do continente americano e a transformou até o século XVIII na "Rainha do Atlântico Sul".

Essas características, fundadoras da identidade baiana, se perpetuaram e se atualizaram no tempo. Trazem até os dias atuais algumas de suas marcas fundamentais. Nas Festas de Largo, todos se encontram (pobres, ricos, classe média, mestiços, negros e brancos, jovens e adultos, iletrados e intelectuais, cidadãos comuns e membros das elites), numa espécie de libertação dos papéis sociais cotidianos para a celebração da identidade cultural compartilhada. Essa libertação de papéis sociais e dos jogos de poder chega à sua maior expressão no Carnaval, que finaliza o ciclo das festas de Largo de forma apoteótica. São dois milhões de pessoas $^{4}$, a cada dia, fazendo a festa em alguns quilômetros de ruas da cidade, numa celebração de música e dança, alegria e festa que parece, naquele momento, abalar as distinções sociais e econômicas. A festa dura uma semana, até a quarta-feira de cinzas.

\subsection{Identidade, interesses, confli- tos e diálogo}

Mobilizadoras do sentimento de pertencimento da população àquela identidade cultural, as Festas de Largo são organizadas há alguns séculos por um arranjo entre as representações comunitárias da sociedade civil - principalmente confrarias ou grupos

\footnotetext{
$4 \quad$ Esses dados são produzidos pelo marketing da Prefeitura da Cidade e faltam estudos científicos mais cuidadosos para definir a verdadeira grandeza da participação popular no Carnaval de Salvador.
} 
religiosos ligados à devoção de cada santo ou a membros dos terreiros de candomblé daquele orixá, em parceria com representantes do poder público municipal e até com o apoio financeiro de empresas locais que buscam promover sua marca associada às festas populares locais. As empresas privadas e suas marcas são, entretanto, mais presentes no carnaval, já que as festas de largo têm a sua dimensão comercial mais restrita ao comércio de comidas e bebidas e artigos religiosos em barracas montadas no Largo ou praça em que acontece a festa.

Ainda que existam conflitos e eventuais jogos de poder, a representatividade da festa junto à população tem impedido até hoje a sua apropriação por um único grupo político, por uma entidade, ou mesmo pelo governo municipal, não havendo, portanto, nenhum ente que reserve exclusivamente para si a organização e muito menos a realização da festa. Os papéis, em geral, são divididos em função da competência legal e da representatividade social e cultural. A prefeitura é responsável por organizar as modificações necessárias para o trânsito, as facilitações de acesso ao local da festa, à organização dos transportes, à disponibilidade de serviços públicos, como postos de atendimento médico, postos de informação turística, etc. O governo estadual fica responsável pela segurança pública e determinação do contingente de policiais disponíveis para atender ao evento. As regras de funcionamento do comércio na festa são determinadas pela prefeitura, que registra e autoriza o comércio ambulante e as instalações das barracas, que, por sua vez, sofrem a fiscalização da vigilância sanitária pelo governo federal. Com isso, as três esferas de governo - típicas de repúblicas federativas como o Brasil - atuam na regulação das festas.

A parte religiosa da festa é organizada por cada representação - dos católicos e do candomblé. Enquanto o padre daquela paróquia lidera a comunidade católica para a organização da missa, procis- são e festa religiosa católica. Os membros dos terreiros de candomblé se organizam e se vestem com suas roupas cerimoniais para participar da celebração do lado de fora da igreja com seus cânticos e cerimoniais do candomblé e também acompanham a procissão, quando há. A mistura entre católicos e praticantes do candomblé acontece, não apenas na procissão, mas também no interior da igreja durante a missa que acontece na festa.

\subsection{A Festa da Conceição da Praia}

Considerada uma das mais antigas festas religiosas do Brasil, a festa da Nossa Senhora da Conceição da Praia acontece desde 1550, o ano seguinte à fundação da cidade de Salvador. Ela é a santa padroeira não só da cidade de Salvador, como também do estado da Bahia e é padroeira de centenas de cidades em todo o Brasil. A imagem de Nossa Senhora da Conceição veio junto com os jesuítas, em 1549, que acompanhavam a comitiva do Governador Tomé de Souza (VARÓN CADENA, 2015).

Em Salvador, ela acontece no mesmo local desde a origem, inicialmente na capela ali construída e, a partir de 1739 , diante da igreja que ali foi inaugurada e que permanece até hoje, depois de várias reformas nos dois últimos séculos. As características atuais, com as barracas da festa de largo existem desde a década de 30 do século XX (COUTO, 2010). No candomblé, Nossa Senhora da Conceição corresponde a Oxum, no sincretismo religioso baiano.

Como é comum nessas manifestações populares, elas dependem de uma constante relação de negociação entre organizadores, poderes públicos e a população. Desde os primórdios, aqui e acolá, conflitos atrapalharam a festa que chegou a ser cancelada por alguns anos. Logo depois de terminada a Guerra da Independência, com a expulsão dos portugueses em 2 de julho de 1823, o Padre Manoel Dendê Bus, atu- 
ante no conflito, pede ao Governador sua nomeação para vigário da igreja (VARÓN CADENA, 2015). A contradição de ter um padre que expulsara os portugueses que contestavam a independência do Brasil até serem vencidos na Bahia em 1823, com a irmandade que era formada exclusivamente por portugueses - esses eram considerados fiéis à pátria brasileira, já que resolveram permanecer aqui, entretanto insatisfeitos pela queda do governo português local - fez com que o padre logo se indispusesse com a irmandade responsável pela organização da festa que, até 1889 continuaria formada exclusivamente por portugueses e seus descendentes. $O$ resultado desse estranhamento foi a não realização da festa de 1824 a 1827. A festa só voltou a ser realizada em 1828 porque o pároco pediu licença para ir ao Rio de Janeiro, deixando a irmandade livre para realizar a festa, sem ter que se submeter ao responsável pela expulsão de tantos patrícios portugueses, incluindo parentes e amigos.

Um outro conflito, ocorreu entre a irmandade e os poderes públicos, em 1915, e mostra o impacto negativo que pode ter, inclusive inviabilizando a festa, quando os poderes públicos, por decisão equivocada ou por incompetência, deixam de cumprir com as obrigações que fazem parte do seu papel na festa. O conflito entre a irmandade religiosa, com sua legítima representação popular nessa esfera, e o que chamamos hoje de governo municipal, com sua autoridade legal e legitimidade política, chegou às vias de fato, impedindo a realização da festa e provocando o seu adiamento.

A irmandade solicitou à intendência apressar a remodelação do asfalto para não comprometer o cortejo. Nada foi feito e isso resultou no adiamento da festa. A rua estava cheia de restos de obra, ocupada 'com matérias imprestáveis, pedras atiradas pelos cantos e vegetação daninha em desvãos, onde a imundície culmina, nauseante mictó- rio público, valhacouto de vagabundos e mendicantes', assim comentou o Diário de Notícias de 3/12 daquele ano. Os festejos foram transferidos para o dia 12 seguinte. (VARÓN CADENA, 2015, p. 127)

A Irmandade do Santíssimo Sacramento e Nossa Senhora da Conceição da Praia, fundada em 1645, continua sendo a responsável pela Igreja da Conceição da Praia e representa na organização da Festa. Nas últimas décadas, a Irmandade tem tido um comportamento conciliatório e esteve fora de todas as polêmicas que envolveram a festa da Conceição, desde o conflito entre setores da imprensa e da opinião pública que condenavam as festas de Axé que aconteciam no entorno da Igreja. Realizado na Marina ao lado, e sem nenhuma relação com os tradicionais festejos, o evento era usado apenas como uma oportunidade de atrair o público jovem para os shows, visto que esse público não se identificava com as características tradicionais da festa. Os eventos de shows acabaram desaparecendo na segunda metade dos anos 2000 , devido a dificuldades crescentes de liberação do espaço pela própria administração da Marina, certamente pressionada por parte da opinião pública que desaprovava o evento.

\subsection{A Festa da Lavagem do Bomfim}

A lavagem do Bonfim é a principal festa religiosa da Bahia e acontece há mais de 200 anos, desde 1754, sempre na segunda quinta-feira de janeiro. Com um cortejo que nos anos de maior afluxo reúne mais de um milhão de pessoas ${ }^{5}$, acontece por seis quilômetros - entre a igreja da Conceição da Praia e a colina do Bonfim. Ela é a segunda maior procissão do Brasil e só perde para o Círio de Nazaré, em Belém do

5 Mesma situação do carnaval. Faltam dados e estudos mais precisos que afirmem a quantidade de participantes da festa. 
Pará, que reúne também mais de um milhão de pessoas. Nas suas origens, esta é uma procissão católica que foi se transformando, graças ao sincretismo religioso de Salvador, num cortejo festivo com danças e batucadas oriundas do candomblé, incluindo até o desfile de carroças levadas por jegues.

Organizada pela Irmandade que é responsável pela igreja e que foi criada desde a sua inauguração, a festa expressa as ambiguidades da identidade cultural baiana. A começar pelo construtor da lgreja, um Capitão do Mar, chamado Theodozio Rodrigues de Faria, comerciante dos mais diversos produtos, suspeito também de contrabando, que escapou de um naufrágio e decidiu agradecer àquele milagre investindo parte de sua própria riqueza na construção da Igreja. Esse feito Ihe garantiu viver com prestígio na cidade de Salvador até sua morte, em 1757 (SANTANA, 2009, 2012).

Até hoje, a irmandade é aberta à comunidade local e participa ativamente da vida do bairro, fazendo jus ao prestígio da Igreja que é a mais querida dos baianos e que tem a maior representatividade cultural, além da religiosa. Essa postura está claramente presente na abertura da Igreja aos atos de sincretismo religioso que caracterizam a festa desde o seu início e que, salvo alguns períodos de exceção, quando inadvertidamente um padre estrangeiro ou mesmo um cardeal autoritário e nada tolerante ao sincretismo religioso baiano, eventualmente, estabeleceram proibições de exibições de outras fés no interior da Igreja, o que jamais foi respeitado ou obedecido pela comunidade.

A Lavagem do Bomfim é a mais importante festa remanescente dos rituais de lavagem das igrejas, que começou no Século XVIII. Nessa época, a sujeira no interior das igrejas e no seu entorno, era comum não só na Bahia como em todo o Brasil. Praças e ruas de terra, sem pavimentação e, ao mesmo tempo, movimentadas por pessoas, comércio e feiras, acabavam gerando muita sujeira que, naqueles tempos, careciam de infraestrutura e condições sanitárias para sua limpeza. Sem água encanada, sem asfalto ou pavimentação no seu entorno, as igrejas dependiam do esforço de muitas mãos para serem limpas. De início, os fiéis, especialmente mulheres, se juntavam para a lavagem das igrejas nas vésperas ou dias de festa. Com o tempo, essa tarefa foi transmitida para os escravos (VARÓN CADENA, 2015).

Uma missa católica é celebrada na igreja do Bonfim enquanto o cortejo se desloca nos seus seis quilômetros de festa. Missa terminada, o cortejo chega às escadarias da igreja, tendo à frente dezenas de baianas com seus jarros de água-de-cheiro, preparada com uma mistura de ervas, seguindo os rituais do Candomblé, que tem a função de retirar as energias negativas. É o culto de Oxalá, um dos principais orixás do panteão do candomblé, acontecendo na frente da Igreja de Nosso Senhor do Bonfim, seu correspondente católico no sincretismo religioso baiano. Então, elas despejam aquelas águas para fazer a lavagem do adro e escadarias da igreja, daí o nome Lavagem do Bomfim.

Entre o início do cortejo às 9:00 da manhã e final da lavagem, no início da tarde, prevalece a atmosfera religiosa e devocional da festa. Depois, assume o profano com braços abertos pela noite adentro, nas imediações da igreja, em barracas de comidas típicas e de bebidas. É a festa que melhor expressa a mistura entre sagrado e profano que caracteriza as festas populares da Bahia.

Nesta festa, um recente incidente expressa os conflitos identitários contemporâneos, através de mudanças de valores na sociedade que acabam impactando nas tradições, recusando parte delas, por não considerar em consonância com a moral ou a política contemporânea. O impasse, 
nesse caso, não envolveu grupos diferentes, mas a ação de um grupo colocando em questão um aspecto tradicional da festa, na verdade expresso no próprio cortejo em si.

A procissão, que mobiliza cerca de um milhão de pessoas, além dos fiéis a pé, tradicionalmente, sempre contou com carroças conduzidas por jegues levando oferendas e santos católicos. O Ministério Público, de Salvador, em 2011, entrou com uma representação contra o uso dos jegues no cortejo por se configurar, conforme a legislação atual, maus tratos a animais. A ação obteve uma liminar favorável do Tribunal de Justiça da Bahia e, com isso, uma festa bicentenária, uma das mais importantes manifestações culturais de Salvador, teve que retirar um dos seus elementos mais tradicionais. A irmandade católica responsável pela festa, evitou participar do conflito jurídico e da polêmica nos meios de comunicação, limitando-se a cumprir a decisão judicial.

Como essa intervenção do poder legal ainda é recente, nos últimos anos os cidadãos e organizadores da festa tentam, judicialmente, a liberação para a volta das carroças e jegues para o cortejo. Em janeiro de 2017, poucos dias antes da festa, uma nova decisão foi estabelecida, permitindo a participação dos animais. Há alguns anos, o caso estava na Justiça. Depois de ter sido devolvido pelo Supremo Tribunal Federal, o processo foi decidido. Apesar dos recursos interportos por ONGs, o TJ-BA decidiu pela liberação da participação dos animais, desde que sob fiscalização da prefeitura, para que não haja abuso ou ato de crueldade.

\subsection{A Festa de lemanjá}

Diferente de outras festas de largo que expressam prioritariamente o sincretismo religioso da Bahia, a Festa de lemanjá, que acontece em 2 de fevereiro, é considerada a maior manifestação pública do candomblé. Ou seja, a maior festa para um orixá fora dos terreiros. Uma tradição que começou em 1924, hoje é uma das três mais importantes festas de largo de Salvador. Antes de prevalecer o aspecto religioso do candomblé, essa festa compartilhava a data, 2 de fevereiro, com muitas outras simultâneas.

Historicamente, a Festa de lemanjá passou por diversas transformações que refletem os conflitos e conciliações entre a Igreja Católica e o candomblé. A festa começa de manhã bem cedo com o lançamento de oferendas ao mar, pelos devotos de lemanjá, o orixá que tem seu correspondente católico em Nossa Senhora dos Navegantes. A outra referência católica é o fato de a festa acontecer na praia, entre duas igrejas católicas do Largo do Rio Vermelho. A entidade da sociedade civil que é responsável pelos rituais da festa é a Colônia de Pescadores. No final da tarde, por volta das 17:00 acontece a procissão marítima, com a participação de dezenas de barcos que vão levar as oferendas para o alto-mar. A festa, como é tradição na Bahia, continua seu lado profano nas barracas, com muita música e dança até tarde da noite.

Criada em 1882, a Irmandade da Gloriosa Senhora Sant'Anna do Rio VermeIho, era organizadora da festa em culto à santa católica e organizou essa celebração até a década de 1930, paralelamente à festa organizada pelos pescadores, celebrando a Mãe D'Água. A partir de então, a festa católica deixa de acontecer e a festa profana passa a ser conhecida como Festa de lemanjá, como permanece até hoje. Por isso, a organização da festa tem como entidade popular principal a Colônia de Pescadores Z-1, que desde 1923 organiza a festa.

Em 2017, dois conflitos anteciparam o evento: a rebelião dos pescadores da colônia contra o seu líder, que chegou a ser preso, acusado de má gestão e suspeita de desvio financeiro dos recursos da entidade. Enquanto não houve julgamento e senten- 
ça, ele permaneceu à frente da Colônia Z1 nos preparativos da festa, que aconteceu com grande sucesso, com a participação cada vez mais ativa de baianos e turistas. Para a população, a controvérsia pareceu mais relacionada a uma disputa pelo poder e prestígio da função do que uma efetiva reação a uma má gestão.

O outro conflito, no mesmo ano, esse envolvendo os poderes públicos, aconteceu em razão de um decreto publicado pela Prefeitura determinando o encerramento de todo e qualquer show musical no entorno da festa até as 22:00. As alegações do Secretário de Cultura do Município, à época, Claudio Tinoco, é que os moradores do bairro, que participam da festa desde o nascer do sol do dia $2 \mathrm{e}$ que acaba em geral nas primeiras horas da noite, passaram a se incomodar com a apresentação de shows em ruas e praças do bairro noite adentro. Apesar das críticas e protestos expressos nas redes sociais, a determinação foi cumprida sem prejuízo da grandiosidade da festa.

\subsection{O Carnaval de Salvador}

O Carnaval foi trazido da Europa para o Brasil ainda no primeiro século da colonização, com o nome de Entrudo, conforme era chamado em Portugal. A essa época, vários países da Europa praticam o carnaval e, principalmente no campo, durante $\mathrm{o}$ ano, cada país tem diversas festas populares, normalmente de origens remotas que, desde tempos imemoriais celebram as estações do ano, ou as boas colheitas ou os deuses pré-cristãos. No Brasil, sucede o contrário. Desde os primeiros momentos, o carnaval, ainda como Entrudo, e depois com o nome atual, vai ser característico das cidades e praticamente inexistente no campo.

Esta uniformidade do entrudo no Brasil sempre sofre adaptações a cada cidade. Em Salvador, por exemplo, a maio- ria negra fazia com que durante o Entrudo os negros, juntos com libertos e mestiços introduzissem na festa hábitos da sua cultura e principalmente as batucadas, típicas de suas danças, festas e cerimônias religiosas (AGIER, 2000). Muitos são os registros entre os séculos XVIII e XIX das decisões de governos municipais de reprimir os excessos de comportamento dos negros durante os Entrudos.

Entre os séculos XVIII e XIX, vão começar a se distinguir dos aspectos dionisíacos dos Entrudos, novas formas de comemorar a festa, em casa, nos salões, buscando uma maior identificação com o comportamento das elites. A introdução do Carnaval no Brasil, portanto, fez parte de um processo de reeuropeização do país, com a chegada da família real e a consequente instalação do poder monárquico em terras brasileiras. Reprimidas as manifestações típicas do Entrudo, o Carnaval à europeia vai se reproduzir por todo - Brasil. Agora um Carnaval "civilizado", feito de bailes e em salões, com as elites usando vestimentas luxuosas e máscaras, com músicas mais tradicionais e longe do baticum dos negros. Serão necessárias algumas décadas de resistência discreta ou mais ostensiva para que o lado popular da festa voltasse a predominar no país.

A influência cultural dos negros vai conferir ao carnaval do Brasil a sua grandeza dionisíaca. Com efeito, a festa terá um significado transgressor entre nós, independente das várias tentativas oficiais de organizá-lo ou torná-lo "civilizado". Da Matta (1979), chama a atenção para a significação do carnaval como momento de exceção, de inversão de regras, de entrega ao excesso, à alegria e ao riso. Nessa disputa entre o carnaval de rua e de clubes, os negros ganharam com a decisão dos clubes de fazerem o desfile nas ruas. Conforme Risério (1981), a apropriação do carnaval pelos negros baianos resistiu às tentativas coloniais de erradicação da 
cultura negra. Ele chama a atenção justamente para a reafricanização do carnaval da Bahia na segunda metade do século $X X$. Essa forte influência negra no carnaval da Bahia continua até os dias de hoje, através dos afoxés e blocos afro, blocos de samba e pagode, e da forte presença de compositores, músicos e cantores negros, com forte influência no mercado da música oriundo do carnaval. Esse protagonismo é dividido com outra vertente do carnaval, representada pelos blocos de trio elétrico e seus artistas, que têm propósitos mais prioritariamente comerciais e muitas vezes são destituídos de vínculos com a cultura negra. Entretanto, mesmo na ausência de maior representatividade da ancestralidade negra, esses blocos, principalmente através do seu repertório de músicas, não escapam à influência dos ritmos de origem da cultura negra, principalmente expressa no protagonismo da percussão e da presença no repertório de músicas que expressam essa negritude, como é o caso do samba-reggae e do pagode.

Em 1950, Dodô e Osmar criam a fobica, um carro aberto, adaptado para a apresentação dos músicos. Trata-se de uma dupla que, de maneira artesanal eletrifica instrumentos de corda, conseguindo uma amplificação e sonoridade que multiplica a sua área de audição. Está inventado o trio elétrico, que será um marco na multiplicação do potencial de participação do público no carnaval. Aos poucos, o som do trio elétrico vai-se tornando a atração principal do carnaval da Bahia (Góes 2000). Em 1969, a gravação de Caetano Veloso, da música de sua autoria, 'Atrás do Trio Elétrico', consagra definitivamente a antiga fobica (a essa altura transformada em caminhões que serviam de palco para grupos musicais maiores) como a marca mais forte do carnaval baiano.

Os trios eram independentes e, contratados pela prefeitura ou por patrocinadores, puxavam as multidões livremen- te pelas ruas do carnaval de Salvador. É a fase áurea do trio Tapajós, trios de Dodô e Osmar e outros. Paralelamente, o carnaval dos blocos vai evoluindo em várias propostas estéticas e musicais diferenciadas, onde os afoxés mantinhas suas raízes africanas com a puxada do ijexá, os blocos de classe média - que começam a crescer e se multiplicar - utilizam músicas de carnaval - a maioria do carnaval carioca-brasileiro, até que surgem os blocos afro, nos anos 1970, numa evolução da proposta estética dos blocos de índio.

O fenômeno dos blocos afro surge ainda no início dos anos 70 . O primeiro deles foi o llê-Aiyê, que procurava representar claramente a negritude baiana. Moura (1987) explica o significado do surgimento do llê-Aiyê, que não seria o primeiro bloco negro, visto que desde os afoxés existiam entidades de maioria negra, mas que, sem dúvida, o llê-Aiyê se estabeleceu como o primeiro bloco afro.

Também com música de percussão, os blocos afro com o tempo foram atraindo milhares de participantes, se caracterizando por uma estética, um ritmo, uma música ligada às raízes culturais africanas, vão ter um impacto no Carnaval da Bahia que só se compara à invenção do trio elétrico em 1950. As suas baterias de dezenas e até mais de uma centena de músicos, com prevalência de tambores, vão se tornar uma atração especial da festa. Associando-se à dança que vão criar e recriar a cada ano, os blocos afro passam a atrair o interesse das classes médias e elites, tornando-se praticamente hegemônicos na estética do Carnaval baiano (DANTAS, 2000).

Os blocos afro introduzem no carnaval algumas inovações fundamentais, como por exemplo desfile com temas e músicas compostas especialmente para a ocasião. O sucesso é tanto que as músicas de rádio no carnaval da Bahia se restringem à produção dos baianos, Caetano 
Veloso, Gilberto Gil (que apesar de poucas músicas feitas para o Carnaval, produziu pelo menos um clássico de grande impacto historicamente na festa, a música Filhos de Ghandi, em homenagem ao tradicional afoxé), Moraes Moreira e Novos Baianos. O vigor, a exuberância, e a sedução do carnaval de rua, marcadamente afro, nunca deixaram de exercer forte atratividade sobre essas elites (MOURA, 2001).

No início dos anos 1990, o carnaval da Bahia já se consolidou como uma fábrica de talentos. Artistas como os precursores da axé music, Luís Caldas, a banda Chiclete com Banana, o bloco afro llê-Aiyê, Margareth Menezes e finalmente o Olodum levam o sucesso do carnaval para o mercado do disco e começam lentamente a abrir brechas no mercado nordestino e depois nacional da música (MIGUEZ, 1996).

É no período 92/93 que o carnaval da Bahia vai se tornar responsável pelo maior sucesso no mercado da música brasileira. Daniela Mercury alcança o primeiro lugar nas rádios de todo o Brasil com a música 'Canto da Cidade', o seu show bate recordes de público do Oiapoque ao Chuí. A artista torna-se a primeira da música baiana a ter um especial sobre a sua música e carreira exibido numa emissora nacional. O sucesso espetacular de Daniela rompe de maneira radical com os preconceitos e barreiras que os grandes centros haviam imposto à música baiana, de origem ligada ao nosso carnaval.

Na contemporaneidade, o carnaval da Bahia, continua sendo o maior do Brasil, com mais de dois milhões de pessoas participando da festa nas ruas da cidade, durante uma semana, com centenas de blocos de trio, dezenas de blocos afro, blocos de percussão e o chamado folião pipoca, que acompanham as dezenas de trios elétricos que percorrem os circuitos da festa na cidade. No carnaval de 2015, bateu-se o recorde de mais de 700 mil tu- ristas $^{6}$ que vieram viver a experiência da festa, o que é um número grandioso para uma cidade que possui pouco mais de três milhões de habitantes.

A festa mobiliza os órgão públicos do município, que organizam o trânsito, as redes de transporte, o comércio ambulante, as autorizações e seus impostos referentes à instalação dos camarotes e aos blocos e trios elétricos que fazem a festa. Mobiliza também órgãos públicos estaduais, que cuidam da segurança pública, nos últimos anos com atuação de mais de 25 mil policiais, incluindo alguns milhares que se deslocam de várias cidades do interior para compor o contingente de Salvador durante o carnaval.

A dimensão econômica do carnaval da Bahia é incontornável: dois milhões de pessoas $^{7}$ por dia participam dos circuitos da festa, centenas de artistas e trios elétricos, milhares de músicos e técnicos, centenas de blocos de trio, blocos afro, afoxés e outras denominações, movimentam toda a rede hoteleira, que bate os maiores recordes de ocupação de todo o ano. Desde recursos de patrocínio, venda de abadás, entradas para camarotes, por um lado, e toda uma cadeia de economia secundária por outro, que vai de clínicas de traumatologia para atendimento de feridos e acidentados, emergências hospitalares, o setor de bares, restaurantes e lanchonetes, a economia informal com milhares de vendedores ambulantes de comidas, bebidas e outros produtos, a economia da festa movimenta na cidade de Salvador mais de um bilhão de reais em uma semana de festa.

6 Dados da Emtursa, incluindo turistas do interior da Bahia, de outros estados brasileiros e do exterior. Mais uma vez, esses dados carecem de maior rigor estatístico.

$7 \quad$ Número estimado oficialmente, conforme notas de páginas anteriores. 
Proporcional à dimensão econômica do carnaval é a sua potencialidade de geração de conflitos a partir de visões diferentes do valor do seu significado cultural, diferentes visões estratégicas para a sua realização, diferentes interpretações do sentido identitário, estético, social e cultural da festa. Instâncias do poder público, especialmente o governo municipal e o governo estadual disputam protagonismo e legitimação política, enquanto respondem às pressões de grupos culturais, empresários e artistas, além de representações de outros setores da economia e da sociedade.

Os artistas e empresários, além de grupos culturais e organizações de caráter associativo, que são os verdadeiros responsáveis pela expressão artística e cultural da festa, disputam suas visões e interesses com os setores governamentais que, por um lado, cobram impostos, fiscalizam as atividades. Por outro, concentram os patrocínios da festa e são cobrados pelos setores artísticos menos organizados ou potentes comercialmente, por um financiamento de suas atividades.

Desde falhas na organização para a mobilidade durante a festa(por exemplo, engarrafamentos de trânsito, difícil acesso a transportes, falta de condições de acessibilidade para pessoas com deficiência) até demora na limpeza dos banheiros químicos, tudo pode ser um motivo para conflito, cobrança, desgaste de imagem, perda de legitimidade, para os atores sociais que representam os poderes públicos.

Os conflitos entre os organizadores da festa podem surgir dos motivos mais inesperados. Em 2016, um conflito surgiu motivado pela venda de cerveja, com exclusividade de marca. Desde que a Prefeitura de Salvador passou a fechar patrocínio com cervejarias para o circuito do carnaval, em 2012, os conflitos têm se multiplicado, gerando protestos e discordâncias por parte dos vendedores ambulantes - obrigados a só vender a cerveja da marca patrocinadora - mas também empresas que administram os camarotes presentes em todo o percurso da folia, especialmente no circuito da Barra. Eles ficam impedidos de exibir, nas fachadas dos camarotes, marcas de cerveja diferentes da patrocinadora da Prefeitura, mesmo sem receber nenhum patrocínio dessa marca. Com isso, as cervejarias que patrocinam os camarotes oferecem valores menores, já que a marca só será vista pelos frequentadores do camarote, perdendo visibilidade para as centenas de milhares de foliões que passam na frente durante o desfile.

No carnaval de 2016, em pleno desfile, houve um protesto e quebra-quebra promovido por vendedores ambulantes de cerveja, por terem sua mercadoria apreendida por ser de outra marca diferente da patrocinadora. O protesto bloqueou a passagem de trios no circuito Barra-Ondina, com os ambulantes bloqueando a via, principal circuito do Carnaval baiano. Os ambulantes queimaram objetos na frente dos trios, após alguns vendedores terem seus produtos apreendidos.

Outro conflito eventual do Carnaval é quando, na sequência das apresentações, um trio elétrico quebra, impedindo todos os outros que vêm atrás de continuar o percurso até o fim. Isso gera algumas consequências negativas para a apresentação, como por exemplo o desgaste dos cantores. Obrigados a continuar cantando enquanto esperam a solução do problema, isso faz com que uma apresentação prevista para quatro horas possa se prolongar por até sete horas, o que é extremamente penoso para esses cantores não só fisicamente, como também prejudica a própria apresentação, com uma repetição de repertório não prevista, que pode cansar o próprio público.

No último dia do carnaval de 2016, na terça-feira, o trio elétrico da banda Torres da Lapa, $12^{\mathrm{a}}$ atração a desfilar no circuito 
Dodô (Barra-Ondina), quebrou e atrasou o desfile de outros blocos. A situação foi motivo de reclamação por parte do cantor Carlinhos Brown, que puxava o bloco 'Camarote Andante', que vinha logo atrás. A reclamação foi seguida por vários outros artistas, a exemplo de Bell Marques, que também atrasou seu desfile em algumas horas.

Enfim, as múltiplas e intermináveis tensões vividas por esses diversos atores sociais do Carnaval da Bahia, dão uma dimensão de importância da festa. Todavia, mostram também a sua função de arena de competição, cujos conflitos são, de certo modo, submetidos ao imperativo do diálogo, em função de uma exigência do consenso social coletivo inequívoco: a realização da festa.

\section{A dinâmica identitária como prática de gestão de festas populares}

A experiência das festas populares de Salvador foi apresentada e analisada a partir das diversas negociações de sentido entre os diferentes atores sociais dentro de uma dinâmica identitária. Isso demanda uma concepção e uma prática mais sofisticada da gestão. Falar da gestão de festas populares pode soar estranho àqueles ouvidos mais acostumados a associar o conceito de gestão ao mundo das empresas e dos negócios. Mesmo os que veem a presença da gestão no universo das organizações públicas ou do Terceiro Setor, podem achar exótico pensar na palavra gestão para festas populares que, por serem relacionadas à tradição e à identidade cultural (HALL, 2006; HOBSBAWM; RANGER, 1983), parecem ser espontâneas e não administráveis. De forma automática, somos conduzidos a pensar que festas populares não são passíveis de gestão, no seu sentido mais tradicional, de responsabilidade de um gestor, um chefe, um líder que coordena e comanda a execução daquela festa.
As festas populares não são administradas por um gestor - como acontece com os eventos culturais, os shows, as festas privadas, os eventos empresariais. Neste contexto, a figura do gestor pesa pouco. O que garante a festa popular é uma série de condicionantes que lhes são peculiares. Por exemplo: a força viva de uma tradição, uma liderança reconhecida que agrega e reitera os valores dessa tradição, uma comunidade ou população que compartilha o reconhecimento da importância dessa tradição e participa anualmente (normalmente as festas têm período certo e se repetem a cada ano) dos acontecimentos que mantêm viva essa manifestação.

O principal desafio da governança de uma festa popular emerge do embate entre os diversos sentidos e interpretações atribuídos à festividade para produzir um engajamento identitário coerente e ativo. Por um lado, os membros da comunidade, que mantêm viva a manifestação cultural, tendem a tentar perpetuar os costumes, rituais e práticas tradicionais. Por outro lado, os poderes públicos e os agentes privados tentam influenciar para que a festa popular se adapte às necessidades e demandas do turismo e dos interesses econômicos mobilizados em torno daquele acontecimento. Além disso, os agentes públicos e coletivos, através de organizações da sociedade civil tendem a buscar que as festas se adaptem aos novos tempos, identidades e valores da sociedade.

As festas populares são marcadas pelas tensões regulares entre as tradições e as novas regulamentações (acordos sociais urbanos), que ganham força em uma rede variada de valores, interpretações e reivindicações públicas. Isso tenciona a gestão de festas que precisa mediar as lógicas interpretativas ancestrais com os novos valores sociais e coletivos. De pequenos conflitos, esses embates podem levar a impasses que podem chegar até a própria extinção daquela festa através do poder 
legislativo. Todas essas visões, ideologias, sentidos e interesses entram em ação em um processo constante de negociação.

Neste contexto, a gestão tende a ser realizada de forma negociada entre sociedade civil, esferas do governo e da iniciativa privada. É configurada em sistemas complexos de governança - muito similar ao mundo das artes (RENTSCHLER, 2015), podendo nascer a partir de uma ou várias organizações associativas. Todavia, a organização da festa - estruturada na forma de sistema complexo - é efêmera. Não existe o dono da festa. A liderança é compartilhada, difusa, orientanda pela identidade cultural, em uma regência em que os líderes expressam legitimidade social, cultural, comunitária ou representação política legal (por exemplo, o prefeito). A prefeitura não pode decidir sozinha; não consegue nem mobilizar o conjunto de atores envolvidos nem financiar toda a festa. Neste contexto, a gestão representa um esforço permanente de negociação de sentidos oriundos das diversas organizações que participam da festa. Essa gestão se articula a partir do entendimento da dinâmica identitária que permeia interesses de grupos específicos, de partidos, de ideologias, buscando uma concertação coletiva visando a realização plena da festa em seu sentido concreto, corporal, ritualístico e simbólico.

Considerando que o tipo de gestor que vai governar a cidade não tem que ser obrigatoriamente o mesmo tipo de gestor que comanda a confraria religiosa ou o bloco de carnaval ou a representação do comércio ou da polícia e da segurança pública, talvez a exigência comum para a atuação desses gestores no processo de governança seja que compreenda e respeite o consenso coletivo e histórico da importância da festa que se impõe a todos eles. Na sua organização, cada gestor expressa modos distintos de gestão, mas quando se engajam na gestão de uma festa popular, devem demonstrar uma concepção identitária da gestão dentro de uma perspectiva de negociação de sentidos e interpretações plurais. Trata-se de um estilo de gestão pautado pela sensibilidade à mediação de interpretações múltiplas em prol de uma dinâmica identitária que viabilize a festa popular.

Com efeito, a gestão de festas populares não se adequa aos modelos vigentes de gestão baseados na liderança individual dentro de uma lógica de controle centralizado, uniformizador e instrumental. A festa não é administrada por uma pessoa, uma organização, mas por um conjunto de representações da coletividade. Distinta da lógica da gestão pautada pelo controle (WATSON, 2002), tradicionalmente difundidas para o universo das empresas, no caso da gestão de festas populares, o conhecimento e uma sensibilidade para as questões históricas e antropológicas se revela estrategicamente determinante para o sucesso da gestão. Portanto, praticar a gestão de festas popular exige um entendimento antropológico da festa e de suas dinâmicas identitárias.

Ancorada em uma dinâmica identitária, a gestão sensível da negociação de sentidos implica uma gestão de conflitos sustentada no diálogo e na aprendizagem (ROTHMAN; FRIEDMAN, 2001). Trata-se de um padrão de gestão que promove a consciência, uma distinção positiva entre os grupos, uma diferenciação e unidade simultânea entre os grupos (FIOL et al., 2009). Por meio de um processo dialógico, todas as partes podem expressar e entender as preocupações profundas que orienta seus conflitos, tanto em seu contexto específico quanto na perspectiva de seus oponentes (ROTHMAN, 1997). O diálogo e a capacidade de negociação é o que encaminha a organização a uma reconciliação de interesses, sentidos e valores, que possibilita a transformação de tendências destrutivas em realidades criativas. $O$ potencial de escuta e reconhecimento nos conflitos de caráter 
identitário é o que torna os conflitos promissores, criativos, transformadores e potenciais fontes de inovação (ROTHMAN, 1997; SWAN et al., 2009). O processo de gestão, neste contexto, pode ser encaminhado em quatro etapas (ROTHMAN, 1997): antagonismo (identificação de diferenças e analise de animosidades), ressonância (reenquadramento reflexivo por meio da articulação de necessidades e motivações compartilhadas), invenção (criação de soluções cooperativas) e ação (estabelecimento de uma agenda compartilhada de cooperação).

\section{Conclusão}

O propósito desta pesquisa foi discutir uma concepção de gestão pautada pela prática da negociação de sentidos - entre os diferentes organizadores da festa - que move a dinâmica identitária. Desenvolvemos um entendimento teórico de dinâmica identitária e uma análise das festas populares na Bahia, destacando a multiplicidade de sentidos e interpretações oriundas dos diversos atores sociais envolvidos na gestão da festa. Essa multiplicidade é geradora de conflitos potenciais que exigem estratégias dialógicas e práticas de negociação, que são compartilhadas por todos os envolvidos no processo de gestão.

Consequentemente, a pesquisa contribui para discutir um caminho conceitual para melhor entender os desafios da gestão de festas populares que emergem, acontecem e enriquecem a vida cultural. Ou seja, pensar as festas populares a partir dessa chave interpretativa significou um movimento duplo: de um lado, conhecer a lógica organizativa que explica o florescimento das festas populares e, de outro lado, ampliar nosso entendimento sobre a gestão desse tipo de fenômeno organizacional. A gestão de festas populares pela ótica da dinâmica identitária exige uma sensibilidade para os aspectos antropológicos e dialógicos da prática da gestão.

\section{Referências}

AGIER, Michel. Anthropologie du carnaval: la vielle, la fête et l'Afrique à Bahia. Paris: Éditions Parenthèses, 2000.

ALVESSON, Mats; LEE, Karen; THOMAS, Robyn. Identity matters: reflections on the construction of identity scholarship in organization studies. Organization, 15(5), p. 5-28, 2008.

ARAÚJO, Alceu Maynard. Folclore nacional I: festas, bailados, mitos e lendas. São Paulo: Martins Fontes, 2004.

BASTIDE, Roger. As Relações Africanas no Brasil: Contribuições a uma Sociologia das Interpenetrações de Civilizações. São Paulo: Editora Pioneira, 1971.

CABRAL, Sandro; KRANE, Dale; DANTAS, Fagner. A dança dos blocos, empresários, políticos e técnicos: condicionantes da dinâmica de colaboração interorganizacional do Carnaval de Salvador. Organizações \& Sociedade, 20(64), p. 145-163, 2013.

CARNEIRO, Edison. Festas tradicionais. Rio de Janeiro: Conquista, 1974.

CARRIERI, Alexandre de P; DE PAULA, Ana P. P.; DAVEL, Eduardo. Identidade nas Organizações: Múltipla? Fluida? Autônoma?. Organizações \& Sociedade, 15(45), p. 127-144, 2008.

CASTELLS, Manuel. O poder da identidade. Rio de Janeiro: Paz e Terra, 1999.

CASTRO JÚNIOR, Luís V. (org.). Festa e Corpo: as expressões artísticas e culturais nas festas populares baianas. Salvador: EDUFBA, 2014.

CASTRO, Armando. Irmãs de fé: tradição e turismo no Recôncavo baiano. Rio de Janeiro: E-papers, 2006.

CAVALCANTI, Bruno César. Novos Lugares da Festa: Tradições e Mercados. Revista Observatório Itaú Cultural, 14 (Maio), p. 10-20, 2013.

CAVALCANTI, Maria L V de C.; GONÇALVES, José Reginaldo S. (org.). As festas e os dias: ritos e sociabilidades festivas. Rio de Janeiro: Contracapa, 2009.

CHARTIER, R. A história cultural: entre práticas e representações. Rio de Janeiro: DIFEL, 2002.

COUTO, Edilece Souza. Tempo de festas: homenagens a Santa Bárbara, Nossa Senhora da Con- 
ceição e Sant'Ana em Salvador (1860-1940). Salvador: EDUFBA, 2010.

CRAIB, Ian. Experiencing identity. London: Sage Publications, 1998.

CZARNIAWSKA, Barbara. Identity lost and identity found? Celebration and lamentation over the postmodern view of identity in social science and fiction. In: SCHULTZ, M.; HATCH, M. J.; LARSEN, M. H. (eds.). The expressive organization: linking identity, reputation, and the corporate brand. Oxford: Oxford University Press, 2000.

DAMATTA, Roberto. Carnavais, malandros e heróis: por uma sociologia do dilema brasileiro. Rio de Janeiro: Zahar Editores, 1979.

DANTAS, Marcelo. Carnaval da Bahia: o conflito entre o público e o privado na arena da festa. [V Encontro sobre Cultura, Identidade e Desenvolvimento: A Festa como Organização] Salvador: Escola de Administração, UFBA, 2018.

DANTAS, Marcelo. Identité, leadership et changement organisationnel dans les blocos afro du carnaval de Bahia. (Doctorat en Sciences Sociales). Unviersité Paris 7, UFR Sciences sociales, 2000.

DANTAS, Marcelo. Olodum: de bloco afro a holding cultural. Salvador: Editora da Fundação Casa de Jorge Amado, 1994.

DANTAS, Marcelo. Três organizações afro-baianas, três modelos, três estilos de liderança. In: FISCHER, T. (org.). Carnaval baiano: negócios e oportunidades. Brasília: Ed. SEBRAE, 1996.

DU GAY, Paul; EVANS, Jessica; REDMAN, Peter (org.). Identity: a reader. London: Sage Publications, 2000.

DUVIGNAUD, Jean. Fêtes et civilisations. Paris: Librairie Weber, 1973.

FACHIN, Fernando F. Organizational identity work in open innovation entrepreneurship. (Ph.D. en Management). HEC Montréal, 2016.

FACHIN, Fernando F.; DAVEL, Eduardo. Reconciling contradictory paths: identity play and work in a career transition. Journal of Organizational Change Management, 28(3), p. 369-392, 2015.

FARIAS, Edson. Ócio e negócio: festas populares e entretenimento-turismo no Brasil. Curitiba: Appris, 2011.
FARIAS, Edson; MIRA, Maria Celeste (org.). Faces contemporâneas da cultura popular. Jundiaí, SP: Paco Editorial, 2014.

FERRETTI, Sergio F. Estudos sobre festas religiosas populares. In: RUBIM, L.; MIRANDA, N. (org.). Estudos da festa. Salvador: EDUFBA, 2012. p. 17-32.

FIOL, C. Marlene; PRATT, Michael G.; O'CONNOR, Edward J. Managing intractable identity conflicts. Academy of Management Review, 34(1), p. 3255, 2009.

FISCHER, Tânia (org.) Carnaval baiano: negócios e oportunidades. Brasília: Ed. SEBRAE, 1996.

GIOIA, Dennis A.; PATVARDHAN, Shubha D. Identity as process and flow. In: SCHULTZ, M.; MAGUIRE, S.; LANGLEY, A.; TSOUKAS, H. (eds.). Constructing identity in and around organizations. Oxford: Oxford University Press, 2012.

GIOIA, Dennis A.; PATVARDHAN, Shubha D.; HAMILTON, Aimee L.; CORLEY, Kevin G. Organizational identity formation and change. Academy of Management Annals, 7(1), p. 123-193, 2013.

GÓES, Fred. 50 anos de trio elétrico. Salvador: Corrupio, 2000.

GROSSBERG, Lawrence. Re-placing popular culture. In: REDHEAD, S.; WYNNE, D.; O'CONNOR, J. (eds.). The clubcultures reader: reading in popular cultural studies. Oxford: Blackwell Publishers, 1997.

GUARINELLO, Norberto Luiz. Festa, trabalho e cotidiano. In: JANCSÓ, I.; KANTOR, I. (orgs.). Festa: cultura e sociabilidade na América Portuguesa, volume II. São Paulo: EDUSP/FAPESB/Imprensa Oficial, 2001.

HALL, Stuart. Identidade Cultural na Pós-Modernidade. Rio de Janeiro: DP\&A Editora, 2006.

HALL, Stuart; DU GAY, Paul (org.). Questions of cultural identity. London: Sage Publications, 1996.

HATCH, Mary Jo; SCHULTZ, M. (org.). Organizational identity: a reader. Oxford: Oxford University Press, 2004.

HATCH, Mary Jo; SCHULTZ, M. Relations between organizational culture, identity and image. European Journal of Marketing, 31(5/6), p. 356365, 1997. 
HATCH, Mary Jo; SCHULTZ, M. The dynamics of organizational identity. Human Relations, 55(8), p. 989-1018, 2002.

HOBSBAWN, Eric; RANGER, Terence (org.). The invention of tradition. Cambridge: Cambridge University Press, 1983.

HOLLAND, Dorothy W; LACHICOTTE, William; SKINNER, Debra; CAIN, Carole. Identity and agency in cultural worlds. Cambridge: Harvard University Press, 1998.

IBARRA, Hermínia. Provisional Selves: Experimenting with Image and Identity in Professional Adaptation. Administrative Science Quarterly, 44(4), p. 764, 1999.

IBARRA, Hermínia; PETRIGLIERI, Jennifer L. Identity work and play. Journal of Organizational Change Management, 23(1), p. 10-25, 2010.

ISAMBERT, François-André. Le sens du sacré: fête et réligion populaire. Paris: Les Éditions de Minuit, 1982.

JANCSÓ, Istivan; KANTOR, Iris (org.). Festa: cultura e sociabilidade na América Portuguesa, volume I. São Paulo: EDUSP/FAPESB/Imprensa Oficial, 2001a.

JANCSÓ, Istivan; KANTOR, Iris (org.). Festa: cultura e sociabilidade na América Portuguesa, volume II. São Paulo: EDUSP/FAPESB/Imprensa Oficial, 2001b.

LAMPEL, Joseph. Converting values into other values: fairs and festivals as resource valuation and trading events. In: MOERAN, B.; PEDERSEN, J. S. (eds.). Negotiating values in the creative industries: fairs, festivals and competitive events. Cambridge: Cambridge University Press, 2011.

LIMA, Vivaldo da Costa. A anatomia do acarajé e outros escritos. Salvador: Corrupio, 2010.

LIMA, Vivaldo da Costa. Cosme e Damião: o culto aos santos gêmeos. Salvador: Corrupio, 2005.

LOIOLA, Elisabete; MIGUEZ, Paulo. Tabuleiros da festa: pequenos negócios \& muitos negociantes do carnaval baiano. In: FISCHER, T. (org.). Carnaval baiano: negócios e oportunidades. Brasília: Ed. SEBRAE, 1996.

MIGUEZ, Paulo. Carnaval Baiano: as tramas da alegria e a teia de negócios. (Mestrado em Admi- nistração). Universidade Federal da Bahia, Salvador, 1996.

MOERAN, Brian; PEDERSEN, Jesper S. (org.). Negotiating values in the creative industries: fairs, festivals and competitive events. Cambridge: Cambridge University Press, 2011.

MORAES FILHO, Mello. Festas e tradições populares no Brasil. Belo Horizonte: Itatiaia ; São Paulo: , EDUSP, 1979.

MOURA, Milton Araújo. Carnaval e Baianidade: Arestas e Curvas na Coreografia de Textos Identitários do Carnaval de Salvador. (Doutorado em Cultura e Sociedade), Universidade Federal da Bahia, Salvador, 2001.

MOURA, Milton Araújo. Faraó: um poder musical. Cadernos do CEAS, 112 (Novembro), p. 10-29, 1987.

PASSOS, Mauro (org.). A festa na vida: significados e imagens. Petrópolis, RJ: Vozes, 2002.

PEREZ, Lea Freitas. A antropologia das efervescências coletivas. In M. PASSOS, M. (org.), A festa na vida: significados e imagens. Petrópolis, RJ: Vozes, 2002.

PINHO, Patrícia de Santana. Reinvenções da África na Bahia. São Paulo: Annablume, 2004.

PITOMBO, Mariella. A diferença como bem universal: a noção de diversidade cultural no discurso da UNESCO. In: ALVES, E. P. M. (org.). Políticas culturais para as culturas populares no Brasil contemporâneo. Maceió: EDUFAL, 2011.

PUTNAM, Linda L. Dialectical Tensions and Rhetorical Tropes in Negotiations. Organization Studies, 25(1), p. 35-53, 2004.

RENTSCHLER, Ruth. Arts Governance: People, passion and performance. London: Routledge, 2015.

RIBEIRO, Cleodes M. P. J. Festa e identidade: como se fez a festa da uva. Caxias do Sul, RS: EDUCS, 2002.

RIBEIRO, Marcelo. Festas populares e turismo cultural - inserir e valorizar ou esquecer? O caso dos Moçambiques de Osório, Rio Grande do Sul. Pasos - Revista de Turismo e Patrimônio Cultural, 2(1), p. 47-56, 2004. 
RISÉRIO, Antônio. Carnaval ljexá. Salvador: Corrupio, 1981

ROTHMAN, Jan; FRIEDMAN, Victor J. Identity, conflict, and organizational learning. In: DIERKES, M.; ANTAL, A. B.; CHILD, J.; NONAKA, I. (eds.). Handbook of organizational learning and knowledge. Oxford: Oxford University Press, 2001.

ROTHMAN, Jay. Resolving Identity-based conflict in nations, organizations, and communities. San Francisco: Jossey-Bass Publishers, 1997.

RUBIM, Linda; MIRANDA, Nadja (org.). Estudos da festa. Salvador: EDUFBA, 2012.

SANTANA, Mariely Cabral de. Alma e festa de uma cidade: devoção e construção da Colina do Bomfim. Salvador: Editora da UFBA, 2009.

SANTANA, Mariely Cabral de. É dia de festa na Bahia: homenagens, ritos e construção da devoção do Senhor do Bonfim. In: RUBIM, L.; MIRANDA, N. (org.). Estudos da festa. Salvador: EDUFBA, 2012.

SAQUET, Marcos A.; BRISKIEVICZ, Michele. Territorialidade e identidade: um patrimônio no desenvolvimento territorial. Caderno Prudentino de Geografia, 1(31), p. 3-16, 2009.

SCHULTZ, Majken; MAGUIRE, Steve; LANGLEY, Ann; TSOUKAS, Haridimos (org.). Constructing identity in and around organizations. Oxford: Oxford University Press, 2012.

SERRA, Ordep. Rumores de festa: o sagrado e o profano na Bahia. Salvador: EDUFBA, 2009.

SILVA, Ariel Lucas; MIGUEZ, Paulo. Cultura, Festa e Cidade: Tecendo Relações. Revista Observatório da Diversidade Cultural, 1(1), p. 19-27, 2014.

SILVA, Tomaz T. da. A produção social da identidade e da diferença. In: SILVA, T. T. da; HALL, S.; WOODWARD, K. (orgs.). Identidade e diferença: a perspectiva dos Estudos Culturais. Petrópolis, RJ: Editora Vozes, 2014.

STOREY, John. An introductory guide to cultural theory and popular culture. New York: Harvester Wheatsheaf, 1993.

STOREY, John. Cultural theory and popular culture: an introduction. London: Routledge, 2015.

STOREY, John. Inventing popular culture: from folklore to globalization. Oxford: Blackwell Publishing, 2003.
STRINATI, Dominic. An introduction to theories of popular culture. London: Routledge, 1995.

SWANN JR.; JOHNSON, William; RUSSEL, E.; BOSSON, Jennifer K. Identity negotiation at work. Research in Organizational Behavior, 29, p. 81-109, 2009.

TINHORÃO, José Ramos. As festas no Brasil CoIonial. São Paulo: Ed. 34, 2000.

TINHORÃO, José Ramos. Os sons dos negros no Brasil: cantos, danças, folguedos: origens. São Paulo: Editora 34, 2008.

VARÓN CADENA, Nelson. Festas populares da Bahia: Fé e folia. Salvador: Edição do Autor, 2015.

WASKUL, Dennis D.; VANNINI, Phillip. Popular culture as everyday life. In: WASKUL, D. D.; VANNINI, P. (eds.), Popular culture as everyday life. New York: Routledge, 2016.

WATSON, Tony J. Organizing and managing work: organizational, managerial and strategic behaviour in theory and practice. London: Pearson Education, 2002.

WOODWARD, Kath. Understanding identity. London: Arnold, 2006.

WOODWARD, Kathryn. Identidade e diferença: uma introdução teórica e conceitual. In: SILVA, T. T. da; HALL, S.; WOODWARD, K. (orgs.). Identidade e diferença: a perspectiva dos Estudos Culturais. Petropólis, RJ: Editora Vozes, 2014.

ZALUAR, Alba. Os homens de Deus: um estudo dos santos e das festas no catolicismo popular. Rio de Janeiro: Jorge Zahar, 1983 